\title{
Qualitative Analysis of Creative Potential of Educational Leaders
}

\author{
Nimira Asif ${ }^{1}$, Sherwin Rodrigues ${ }^{2}$ \\ ${ }^{1}$ Aga Khan University School of Nursing and Midwifery, Pakistan \\ ${ }^{2}$ Aga Khan University Institute for Educational Development, Pakistan \\ Correspondence: Nimira Asif, Aga Khan University School of Nursing and Midwifery, Pakistan
}

Received: August 11, 2015 Accepted: August 28, $2015 \quad$ Online Published: September 23, 2015

doi:10.11114/jets.v3i6.1026

URL: http://dx.doi.org/10.11114/jets.v3i6.1026

\begin{abstract}
The research study was carried out in a private university with course participants of Masters of Education (MEd) having a major in the specialization of Educational Leadership and Management. The purpose of the study was to enhance the creative potentials of educational leaders. Creativity provokes diverse thinking to make something novel which can improve the standards of living of an individual with the changing times. Striving for effectiveness, efficiency and quality in every aspect of life draws imagination towards the need for creativity in an educational leadership role because leaders influence minds and act as change agents (Kaufman, 2005). According to Lagari (2010) the former chairman of Higher Education Commission Pakistan, all leaders need to enhance creativity to facilitate 'out of the box' solutions. In order to enhance this emerging need of creativity for educational leaders the study was conducted with action learning as the methodology to enrich the creativity of educational leaders (as education is the key to progress). The tools to collect the relevant data were semi-structured interviews, exercises on creativity and focus group discussions. The process of data collection had three phases. In the first phase semi-structured interviews took place on the basis of which the participants were given some worksheets to enhance their creative potentials. The worksheets included activities for idea generation, lateral thinking, re-layering, etc. The second phase included focus group discussions (action learning phase) in which all three participants shared their professional life problems and explored alternative solutions. In the last phase semi-structured interviews were conducted, once again, to ascertain the application of participants' learning. The findings and analyses revealed that in order to face the challenges of the $21 \mathrm{st}$ century, educational leaders need to equip themselves with creative thinking skills. It also emerged from the interviews that the educational system by which participants have studied, has hindered their creativity. Therefore, educational leaders need to enhance their own creative potential which has proved to be beneficial for organizational growth and development by practicing creative thinking exercises and creating action learning groups.
\end{abstract}

Keywords: creativity; educational leaders; creative potential

\section{Introduction}

Creative thinking is the ability which is possessed by all human beings and it flourishes or diminishes with the experiences and environment in which we live. In order to meet the needs of a global world, educational leaders require being equipped with the skills which help them to adapt to the changes in the $21^{\text {st }}$ century. The purpose of this study is to highlight the creative thinking skills of educational leaders, specifically those affiliated with schools and colleges.

The ability to adapt with the pace of time is always there in human beings. Whether it is the past, the present or the future, the instinct to survive in changing times is ever present. As Gupta (2006) said that nothing can contribute more to the progress of a society than fostering the creative performance of the people. This nature of survival with the changing times can be possible with a sense of bringing change and demonstrating an ability to be creative. Plants and animals as living creatures try to live with their instincts for the fulfillment of their basic needs but humans have the capacity to move forward beyond their basic needs because of their ability to plan and bring change. These abilities also drive humans to be creative and innovative to keep up with the changing times. Creativity invites the mind to think diversely in order to make something novel to improve the standards of living from time to time. Attempting to strive for effectiveness, efficiency and quality in every aspect of life draws our imagination towards the need for creativity in a leadership role because leaders influence minds and act as change agents (Kaufman, 2005). According to Lagari (2010) the former chairman of the Higher Education Commission Pakistan, all leaders need to enhance creativity to facilitate 'out-of-the-box' solutions. This notion suggests that there is a solution to every problem and that, as leaders, we need to 
think in a creative way. In order to enhance this emerging need for creativity by leaders, a study was conducted using action learning which enriched the creativity of educational leaders (as education is the key to progress). The research participants were from a private university - a group of course participants specializing in educational leadership and management in the MEd programme.

This paper discusses the findings of a research study that was carried out as at a private university in a developing country. The findings portray a general understanding of the research participants about creativity and its relationship with educational leadership. The background and research question are mentioned next.

\section{Background and Problem Statement}

Creative thoughts are always there in the mind; it is helpful to build such thoughts for the betterment of society and to use the mind in a positive direction. For example, Haavisto (2005) asserts that creativity is a driving force for the development of society. Along with creative ideas, education has been the fundamental need of every society (Simon, 1979). Education - whether it is past, present or future - is vital for the growth of all nations. In order to move forward for educational strength powerful minds are needed that have the ability to think with alternative ideas and offer something novel to the society. Several educational reforms and structures are proposed and implemented but sustainability, accountability, monitoring and evaluation seem hazy and the revised policy also addresses this issue (NEP 2009, p.62). In such circumstances creative leaders are needed who possess the ability to think out of the traditional dimension to improve a country's educational standards. To support this stance, Barber (2010) discussed the possible future of Pakistan (the developing country where this study was carried out) which, according to him, would comprise around 340 million people by the mid- $21^{\text {st }}$ century. He clearly mentioned the need for well-educated, imaginative, innovative and creative people. Many consultancy firms have arranged creativity and leadership workshops and trainings, for example, creative leadership conferences. The first author has seen that leaders have identified the need for being creative and have actively transformed the people and practice. This study has contributed to the training and development of educational leaders; it has allowed insights to the thinking about the facilitating and hindering factors of creativity enhancement in a developing world context. The study has guided the participants to actualize their creative potentials and has examined closely three important ingredients of promoting creativity: organizational motivation, resources and management practices (Amabile, 1996).

Field visits undertaken by the first author as part of her two-year full-time Masters of Education programme at a private university indicated that substantial input was provided in terms of teacher training and educational district officers' development, infrastructural change of some schools, improvement of schools as model schools by the city district government, formation of a computer lab, etc. to improve the quality of education. Despite this, achieving the target of Millennium Development Goal (MDG) which says Education for All (EFA) has not been attained. This is because improving the physical infrastructure and devising strict hierarchical systems are not the only responses towards MDG. There is a need to work on the core qualities of leadership and creativity. Therefore, the following research question was derived out of this background:

How can the creative potentials of educational leaders of a developing country Pakistan be enhanced?

\section{Research Method and Data Collection}

For this study action learning methodology has been used. Morgan (1997) was the first inspiration for the first author to apply this methodology. Application of this methodology will facilitate in enhancing the potential experiences of those individuals who are involved in action learning (McGill \& Brockbank, 2004). As suggested by the term 'action learning' itself, this method involves both learning and action. For transformational change (Marsick \& O'Neil, 1999) this method is beneficial. McGill and Brockbank (2004) also assert that transformational change can take its roots when individuals have a high post in an organization and have experienced action learning.

The first author approached participants of the educational leadership and management course in a private university and sought permission to conduct the study to which three people voluntarily consented. The research study was about enhancing the creative potential of educational leaders. Hence, the research participants were asked to fill some worksheets related to creative thinking. The worksheets were allocated as per participants' needs to learn a specific aspect of creativity. This need was verbalized by the research participants in the first phase of semi-structured interviews and all three wanted to learn some techniques to generate ideas. All three participants shared their ideas in the activity sheets which included exercises for generation of ideas, lateral thinking, relayering and brainstorming. However, all the research participants expressed their interest for activities that promoted the generation of ideas. Once this activity ended the participants took part in a focus group discussion which highlighted their divergent thinking. All participants were helped to discuss their experiences of leadership and creative potential within the focus group discussion which was the actual application of the action learning methodology. The group was formed for the twofold purposes of sharing the problems that the participants faced during their leadership role in their own institutes, and 
subsequently eliciting the suggestions of colleagues that helped the person (the problem presenter) to plan action accordingly. In an action learning set which was a triad, one was the presenter (of the problem), one was the enabler who probed the presenter to come up with his/her own solution to the problem and the third person was the observer who gave feedback to the presenter and the enabler about the process. This phase allowed the participants to start thinking about solutions in a more innovative manner. Thus, research participants tried to implement the learning from the idea generation worksheet. This was followed by semi-structured interviews that focused on the application for educational leadership and participants' changed perceptions about creativity. Semi-structured interviews permitted to probe the participants for an in-depth understanding and clarify concerns related to the research study. The participants' views about creativity and its application in their lives as leaders were the major areas of inquiry. On the other hand, questions which revealed their pattern of initiating, developing and sustaining any academic assignment were also included. This unveiled the participants' needs of enhancing a particular skill of creativity. Both the interview guide and activity sheets were piloted before administration.

\section{Validity and Reliability}

Multiple sources of data collection such as semi-structured interviews, observations, focus group discussions and document analysis (exercise sheets) complemented one another for the enrichment of data generated. Merriam (2007) offers some strategies for this purpose. The first strategy is 'triangulation' and she cites Denzin (1978), in which he proposes four types of triangulation: the use of multiple methods, multiple sources of data, multiple investigations or multiple theories to confirm emerging findings. The second strategy is 'member check' which is also called respondent validation. According to her, this is the most probable way of ruling out the possibility of misinterpreting what the participants say and do. The third strategy of Merriam that was used was 'peer review' where it is asked from colleagues to scan some of the raw data and assess whether the findings were plausible based on the data. During this process anonymity and confidentiality were maintained.

\section{Variables}

For this study the dependent variable is creative ideas or thinking which is dependent on the creativity enhancement tools (see Appendix A).

\section{Data Analysis}

Creswell (2003) states that qualitative data require sensitivity to detail and context, as well as accurate information and ways of exploring themes and ways of understanding information. Therefore, data transcription commenced immediately after data collection whereby the first author repeatedly listened to the recordings in order to avoid missing out any important element related to the research study. After compiling the data, findings were synthesized under appropriate themes. These findings were then categorized according to the research question. A description of the findings and a detailed discussion of these are provided next.

\section{Creativity in General}

\subsection{Understanding of Creativity}

The following are the perceptions of participants about creativity.

\subsubsection{Being Different}

Participants considered being creative as anything that appears odd or anything that has been seen for the first time. During the interview phase participant ' $\mathrm{C}$ ' said, "Something very different nobody has ever done" (Interview, February $22,2011)^{1}$. Hence, it is important to note that people regard 'different' as the thing which is creative or anything that they have not seen or rarely seen in life.

\subsection{2 'Out of the box' Thinking}

Something that is observed rarely or away from daily routine is considered as 'out of the box' thinking. The same idea emerged during the interview with participant 'B': "Creativity for me is to have 'out of box' thinking" (Interview, February 18, 2011). Another participant (C) held the same view: "I think creativity is something thinking 'out of the box" (Interview, February 22, 2011). This shows that something that deviates from the normal task is considered as creative. That is, moving beyond the four walls of the box and thinking more deeply and imaginatively.

\subsection{Relation of Creativity and Educational Leadership}

All the research participants responded in a positive manner to the strong relationship between creativity and educational leadership. The overall finding that emerged from the analysis of this part of the data revealed that there is a

\footnotetext{
${ }^{1}$ Responses from all the research participants are included verbatim
} 
strong relationship between creativity and educational leadership. Findings are discussed next under several themes.

\subsubsection{Challenges of the $21^{\text {st }}$ Century}

It is thought that creative thinking will bring out new ideas for development in the $21^{\text {st }}$ century, as it is the time of a hi-tech world and survival is only possible when one is able to think creatively. Participant 'B' said:

The world is changing so fast and because of IT and the knowledge society they will be facing a lot of problem which new problem which they may encounter that going to be the biggest challenge and that's why we need to bring up students who have critical thinking and creativity. (Interview, February 18, 2011)

This depicts that creative thinking is the tool to face the challenges of the $21^{\text {st }}$ century. As the development process has accelerated in the present time leaders may be considered ineffective if they maintain a traditional outlook. In the same vein participant ' $\mathrm{C}$ ' stated, "For enjoyment in the work to come out from the routine and traditional things creativity is needed" (Interview, February 22, 2011).

\subsubsection{Developing Motivation}

It is commonly seen that leaders motivate employees so that it brings a positive outcome for the development of the organization. A similar idea was emphasized by research participant ' $\mathrm{A}$ ' as she said, "It means charm for school is not there so schools are right now very boring places and students are going there, so they going for their friends they do not have any intrinsic motivation for learning" (Interview, February 18, 2011). This shows that students at school have the motivation to come to meet friends but not to meet with the intent of achieving the academic goals. Here the role of a leader is to motivate students by developing the teaching learning practices of teachers. As participant ' $\mathrm{C}$ ' said, "Teaching and learning is creative process and leaders have to provide that learning environment to teachers" (Interview, February 22, 2011). This means that if educational leaders are in favour of creativity then their own support will increase.

\subsubsection{Sustainability of the Organization}

Vision for an organization includes its sustainability in the future with the changing times. It is the leader who has to look for such aspects that help people to develop and sustain best practices. It is for this very reason that the ability to think about alternative solutions and thinking in all dimensions allows the organization to sustain itself. Participant ' $\mathrm{C}$ ' expressed the views as, "Other than this, educational leaders have to prepare future leaders so that they can have a second line when they are not present, the teachers are there. Also creativity is important for the sustainability of organization" (Interview, February 22, 2011). It brings to light that leaders are the ones who not only strive for the development of an educational system but also for its sustainability.

\subsubsection{Team Building}

One of the qualities that are required for educational leaders is team building. Achieving the aim that these leaders look for is not possible without team effort. Therefore, team collegiality and its efficiency are very important and a creative leader will guide the team for unleashing their creativity. As participant 'B' said:

I think if one is creative then one can also help to work in a team because the creative problem may not be the creativity may not be just bringing in new ideas but findings ... may be there are team problems so working creatively to resolve those team problem[s] is also an important aspect of being creative ... so that people all agree to work as [a] team or are happy to work as a team. (Interview, February 18, 2011)

The leader is a team builder and it may be inferred from the preceding statement that if a person is creative then he or she will be able to bring new perspectives to work on and will guide the team to work in a favourable environment. The same participant was sharing her view about leading a team and in conclusion she stated:

I believe is only you work with the team and you are able to support them to go with that idea and it becomes success so you understand the creativity of the person and appreciate and help them to bring out creativity" (Interview, February 18, 2011).

\subsubsection{Preparing Future Leaders}

Leaders are the ones who prepare leaders of the future; they lead and facilitate others to lead in their absence. This is very relevant in the educational system of Pakistan as well because often a leader leaves the job and the team suffers due to the absence of a leader. Research participants also agreed with this point: "Leaders have to be creative. Other than this educational leaders have to prepare future leaders so that they can have second line when they are not present the teachers are there" (Interview, February 18, 2011). It shows that leaders are the ones whose ideas always remain with the team so that they can work smoothly without a leader's physical presence. Many times when the principal of an institution retires, the school feels a loss but if that leader had transformed his/her best practices into the other teachers 
the school would not have felt such a loss.

\section{Discussion of the Findings}

\subsection{Understanding Creativity}

There is no rigid definition available for creativity; it differs from people to people and from one context to the other. Most of the participants thought that being different was considered as creativity. It is similar to the understanding of university students, where the study about the conception of creativity among business students took place by Petocz, Reid and Taylor (2009). Many students conceptualized that creativity was an ability to be different. The researchers regarded this view as a narrow conception of creativity whereas a person who thought that creativity was "thinking out of the square" had a broader view. One reason for a narrow view of creativity may be that the term is rarely discussed in the classroom and in the context of teacher trainings. During the present research study the first author had an opportunity to present "creative teaching" for teachers of social studies from the forum of Professional Teacher Association Network (PTAN). The session was received positively by the participating teachers who emphasized the teaching of creativity among their group and for students as well. The research studies mentioned hitherto provided the ideas that brainstorming and group work were effective for enhancing the creative potentials of a person. This leads to the reflection that ideas are there within us but triggers are needed and if leaders provide a stimulating environment then education personnel will bring these ideas to the forefront.

It was evident from the analysis that the educational system of Pakistan does not allow learners to think creatively and has been identified as one of the hindering factors to creative thinking. It was also evident from the data that research participants did not try out new solutions due to the fear of being wrong and owing to a lack of confidence. If leaders did not regard themselves as creative then how could they envisage enhancing these potentials among their colleagues and employees? Yamamoto (2007) also regarded this situation that we are in search of sober work which is why sometimes ideas are developed but there is a lack of 'will' to implement these. He regarded sober work as something aesthetic and functional as well. It might happen that a narrow view or a disregard of being creative may influence one's role as a motivator of creativity and thus, students' creative potentials are also suppressed. Therefore, creativity has a strong link with educational leadership because actions influence the educational system and if there is a wish to enhance creativity among the student body, then it is a prerequisite to discover our own potentials and ways of defining creativity.

\subsection{Creativity and Educational Leadership}

The data highlighted several aspects for educational leadership and its link with creativity. Participants noted that creativity would greatly help to face the challenges of the $21^{\text {st }}$ century. Furthermore, experiences of the future would be different to those encountered in the $20^{\text {th }}$ century because of the advancement of information technology and knowledge society. Consequently, it is important to ponder the reason why creative people are more equipped to respond to challenges; the reason may be that creativity allows thinking more deeply and imaginatively. D'Cruz (2008) notes that currently the world is facing a wider array of competitive pressures than ever before and in order to survive, the organizations must be constantly changing and innovative. It also supports the data which indicate the need to come out from the routine work in order to keep abreast with the outside world. It is the time, therefore, to react in a proactive manner. D'Cruz also suggests that the idea of creativity must come from the highest level of management to the lower levels and this supports the need of enhancing creative potentials at the leadership level. Therefore, it is important for leadership to understand the notion of creativity and help in enhancing this hidden potential. This will allow educational leaders to tap the creativity of teachers and other colleagues. Amabile, Burnside and Gryskiewicz (1999) define the support for organizational creativity as a culture which motivates creativity by reward and recognition, fair judgment of creative work and a shared vision. This idea can be related with the sustainability of the organization's development. The reason would be that if the leaders allow the flow of ideas and appreciate the person's creativity, the employees would most likely sustain their work. As Shalley, Gilson and Blum (2000) argue that if leaders know how to use the creative potentials in the workplace it will lead to job satisfaction and increase the retention rate. It is very relevant in today's situation in which brain drain is just occurring due to a lack of job satisfaction. Many teachers leave their workplace and they sometimes leave the profession. Bhatti (2011) described the educational crisis in Pakistan and has suggested the need for a politically-led innovation and change in leadership from bureaucrats to elected politicians. This shows that there is a need of change and creativity will be a supportive tool to achieve this goal.

The article of Bhatti (2011) is an eye-opener to the educational system in Pakistan. Central to his approach is the belief that the chaotic conditions at the edges of organizations can be constructively harnessed. It leads to another dimension of creative leadership which is the need to build teams. It was also highlighted in the data that leaders were the ones who created teams and they facilitated in unleashing the creative potential of each member in the team. The abilities to build effective teams and have collaboration across boundaries are considered as the most important skills of leaders 
(Martin, 2007). This shows that educational leaders need to enhance a team's output and also the cross-boundary relationships such as public-private partnerships, communities and parents as partners. Moreover, Harris (2009) also asserted that creative thinking was not an easy task; it required considerable thinking about the past, the mindset and the patterns. Creative leaders were the ones who connected people and ideas. It is imperative to practice creativity because if there is the intent to excel in achieving the educational goals then there is a need to change our thinking processes.

Another key area that emerged during data analysis about creativity and educational leadership is preparing future leaders. It is commonly seen that once a leadership position has been secured we start thinking of our own survival and try to retain this position for an extensive period of time. During an academic school visit during the MEd programme the first author found that, on average, a principal held that position for 15 years. This may reflect the traditional way of moving an institution forward; on the other hand, during another visit the first author found that the absence of the head teacher created chaos in the school regarding managing the school routines. Why such circumstances arose may be because future leaders were not developed or there was a lack of planning regarding the future leadership of the institution. The crisis of leadership is there in both the public and private sectors. The next generation of leaders cannot be created overnight; schools need a dynamic movement by investing in talented leadership in the present time.

\section{Conclusion}

To conclude, future leaders will be recognized by their ability to collaborate and be creative. Therefore, training leaders for developing the future of the organization is needed and development requires planning and implementation both of which can be facilitated by creativity. Riquelme (2000) has studied the impact of creativity on strategic planning. He found that creative problem-solving had a marginal support on strategic plans. He also suggested that people having narrower perspectives of things have benefitted from the approach of learning for creativity. It means that learning for creativity has proved to be beneficial for organizational growth and development. As it has proved in the study that initially the participants were having a narrow definition of creativity, they were not considering themselves as creative; later on they identified that they already had that potential of being creative. They just needed a boost to work on creativity enhancement tools.

\section{References}

Amabile, T. M. (1996). Creativity and innovation in organizations. Harvard Business School, 9, 239-396.

Amabile, T. M., Burnside, R. M., \& Gryskiewicz, S. S. (1999). User's manual for keys: Assessing the climate for creativity. A survey from the center of creative leadership. Center for creative leadership: Greensboro, NC.

Barber, M. (2010). Education reform in Pakistan: This time it's going to be different. http://www.brookings.edu/ /media/Files/events/2010/1104_education_pakistan/BarberPakistan_Education\%20Pap er.pdf

Bhatti, A. (2011). The education crisis. Dawn, p. A 17.

Creswell, J. (2003). Research design: Qualitative and quantitative approaches. London: Sage Publication.

D'Cruz, P. (2008). Thinking Creatively at Work a Source Book. LosAngeles: Sage.

Gupta, K. P. (2006). Education for creativity. New Delhi: Cosmo Publication.

Haavisto, V. (2005). Towards a creative society: Embracing the diversity of creativity. University of art and design, Helsinki, Finland. http://www2.uiah.fi/joiningforces/papers/Haavisto.pdf

Harris, A. (2009). Creative leadership: Developing future leaders. Management in Education, 23(1), 9-1. http://dx.doi.org/10.1177/0892020608099076

Kaufman, B. (2005). The Leader as Change Agent. University Business, 8(3), 53-54.

Laghari, J. (2010). “Creativity.” E-mail to Nimira B. Noorani. 5 Sept. 2010.

Marsick, V. J., \& O'Neil, J. (1999). The many faces of action learning. Management learning, 30(2), 159-176. http://dx.doi.org/10.1177/1350507699302004

Martin, A. (2007). What's next: The 2007 changing nature of leadership survey. Center for Creative Leadership. http://www.ccl.org

McGill, I., \& Brockbank, A. (2003). The action learning handbook: Powerful techniques for education, professional development and training. London: Routledge.

Merriam, S. B. (2007). Qualitative research and case studies applications in education. San Francisco: Jossey-Bass Publications.

Morgan, G. (1997). Imaginization: New mindsets of seeing, organizing and managing. San Francisco: Sage Publication. 
National Education Policy (2009). Ministry of Education, Government of Pakistan.

Petcoz, P., Reid, A., \& Taylor, P. (2009). Thinking Outside The Square: Business Students' Conceptions Of Creativity. Creativity Research Journal, 21(4), 409-416. http://dx.doi.org/10.1080/10400410903297998

Riquelme, H. (2000). How to Develop More Creative Strategic Plans. Creativity and Innovation Management, 9(1), 1420. http://dx.doi.org/10.1111/1467-8691.00154

Shalley, C. E., Gilson, L., \& Blum, T. C. (2000). Matching Creativity Requirements and the Work Environment: Effects On Satisfaction And Intentions To Leave. Academy Of Management Journal, 43, 215-223. http://dx.doi.org/10.2307/1556378

Simon, J. (1979). Education in society. Cambridge University Press, Education and Society in Tudor England. http://www.learningcity.org/society.html

Yamamoto, K. (2007). Too clever for our own good. Lanham, MD: University Press of America. Education in Society. http://www.learningcity.org/society.html

\section{Appendix A}

\section{Exercises: Ideas Generation}

1. All the uses of table

2. Create a word: ology.

3. What strikes your mind when you read the following words?

A difficult employee

A class without a teacher

4. Relate the opposites: dark and light

5. Which product requires improvement? (Any daily use item)

\section{Exercises: lateral thinking}

1. Forced analogy: organizations as mother.

List most known attributes of a mother:

Link mother with an organization.

2. Challenging assumptions: hotels do not charge for food

\section{Exercises: Relayering}

1. Recall all the colors you have seen from morning to this time:

2. Force fitting: think of attributes of the following words separately. Then see the associations; cake, shark and poverty

\section{Exercises: fantasy trials}

1. Day dreaming: Close your eyes for ten minutes. Share the thinking process.

2. Weave a story: snowfall and the dog bark

\section{Exercises: brainstorming}

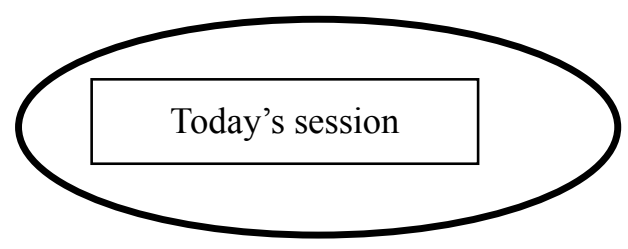

Appendix B

Creativity Questionnaire 


\section{Before Focus Group}

1. How do you define creativity?

2. What do you already know about creativity?

3. How do you think of yourself as a creative person?

4. What are the factors that help or hinder your creativity?

5. In the past have you ever experienced yourself as a creative person?

6. Think of the last assignment. How many different ideas did you apply? What were the ideas you started with? If you have been given a chance to review, how will you improve it?

7. What is the relationship between creative thinking skills and educational leadership?

After Focus Group

1. How will you apply the creative thoughts at your workplace? (Once you know some ways to enhance creativity.)

2. Can you compare yourself before and after learning some strategies to enhance your creative potentials?

3. How do you feel about the process of learning for creativity?

4. Can you make or modify your ways of leading a group of people?

5. Can you plan a school (or an education system) which is creative?

This work is licensed under a Creative Commons Attribution 3.0 License. 